\title{
Competitive Advantages of Lecturers
}

\author{
$1^{\text {st }}$ Baharuddin \\ Faculty of Islamic Religion \\ University of Muhammadiyah Makassar \\ Makassar, Indonesia \\ baharuddin@unismuh.ac.id \\ $4^{\text {th }}$ Diah Yuli Sugiarti \\ Universitas Islam 45 Bekasi \\ Bekasi, Indonesia \\ Diyah.ys@gmail.com
}

\author{
$2^{\text {nd }}$ Donna Sampaleng \\ STT IKAT Jakarto \\ Jakarta, Indonesia \\ donnawana@yahoo.com
}

\author{
$5^{\text {th }}$ Rhini Fatmasari \\ Universitas Terbuka Jakarta \\ Jakarta, Indonesia \\ rhiens29@gmail.com
}

\author{
$3^{\text {rd }}$ Marislinda \\ STIP-AN Jakarta \\ Jakarta, Indonesia \\ Marislinda.adris@gmail.com
}

\begin{abstract}
This study aims to find out the lecturers' competitive advantages in five universities (public and private). This study employed a qualitative approach by applying a descriptive method. The instrument in this study was the researcher as the main instrument. Data were collected through interviews, observations, and documentation. The results showed that: (1) the lecturers' competitive advantages in education, research, and teaching must be formulated in detail and implemented in lecturers' performance, (2) the lecturers' competitive advantage in education, research, teaching must be in accordance with the performance that has been formulated and planned, and ( 3 ) the results of the lecturers' competitive advantage about education, research, teaching are applied in universities. The recommendation of this study is that leaders in the Universities, faculties, and departments in carrying out the activities of Tri Dharma (Three Principles of Higher Education) should refer to guidelines, rules, terms of reference, policies that have been approved as guidelines in carrying out education in Higher Education.
\end{abstract}

Keywords; Competitive, advantage, and lecturers

\section{INTRODUCTION}

Competitive advantage is the result of one's performance in describing the importance of a competition. For a lecturer, this competitive advantage is defined as the competitive strategies which are performed into specific steps needed to gain competitive advantages. According to Porter, competitive advantage is a condition where a lecturer is able to create values which exceed the costs incurred by the buyers. In this case, values mean what is willing to be paid by buyers, and the competitive advantage is from the offered cost which is lower than the cost offered the competitors but the advantages equal or give more unique advantages, instead of merely offsetting high prices. A competitive advantage is signed by a condition where a lecturer is able to present some advantages and to encounter a competition better. In short, a competitive advantage exists when a lecturer is able to give a cost advantage or present a differentiation advantage. Competition is the essence of a lecturer's success or failure. Competition determines the accuracy of a lecturer's activities that may support his or her performance such as innovations, integration, cohesive cultures or good implementation.
Competitive strategy is the search for a beneficial competitive position in an industry.

Michael Porter states that competition is the essence of a lecturer's success or failure where around him or her there are many persons who can compete to attain higher levels. This means that a failure depends on the bravery of the lecturers or institutions to compete. It is impossible to succeed without any support or facility provided by the institutions or lecturers. Competition determines the accuracy of activities conducted by the people who support their performance such as innovations, cohesive cultures or good implementation. According to Schemerhorn that:

Competitive advantage is an ability to do things better than one's competitors. when these are things others cannot quickly copy or easily learn to do, the competitive advantage becomes more sustainable over time.

Competitive strategy is aimed at keeping a beneficial position and the position may be maintained by individual powers that determine the industrial competition institutionally. According to Susan E. Jackson Michael A. Hitt Angelo S. that

Competitive advantage is gained only when the organization selects or develops these resources and structures work tasks and the reward system in ways that motivate the team to perform well and thereby contribute to organizational effectiveness

An institution differentiates itself from its competitors based on the competitive units.

Competitive advantage is created by being different in ways that are meaningful to customers. For that reason, it is important for firms to embrace the difference, to go against the grain, to value differentiation externally and internally.

Porter in his book Competitive Advantage (trans.) describes competitive advantage as follows: Competitive advantage principally develops from values which are able to be created by a lecturer for his or her buyers where the values exceed the cost spent by the lecturer to create the values. Value is what is willing to be paid by the buyer, and the competitive advantage is from the offered cost which is lower than the cost offered the competitors but the advantages equal or give more unique advantages, instead of merely offsetting 
high prices. Dealing with lecturers, there are two types of competitive advantage namely and cost competition and cost differentiation.

It is in line with Cravens' statement that a lecturer gets a competitive advantage by giving added values to consumers through:

a. Price which is lower than that given by the competitors for the equivalent benefits.

b. Uniqueness of benefits that may cover a higher price

c. Therefore, it can be concluded that a competitive advantage may be obtained if the lecturers are able to give higher values to the consumers in the form of the offer of lower price or to give uniqueness of benefits that may cover high price..

In other words, competitive advantage of state and private higher education deals with how higher education really applied their generic strategies in practical activities. According to Wagner in his Journal, it is stated that:

Competitive advantage is defined as the outcome of firms' successful strategy implementation. It can be obtained by offering superior value to the customer through either unique benefits that offset a higher or lower price than competitors for equivalent benefits.

Meanwhile, according to Phapruke Ussahawanitchakit that competitive advantage is about knowledge and the ability to use it to develop and improve products and services". In other words, the concept of value creation lies at the heart of competitive advantage. Possessing and maintaining competitive advantage of higher education is beneficial for attaining high performance. Another opinion is presented by Tien et all on the competitive advantage of lecturers that:

To achieve a competitive advantage, firms need to create positive value which equals or exceeds their competitors and outperforms other competitors. Thus, they have taken their competitive advantages for supporting excellent business performance. In building competitive advantage, both low cost competition and product differentiation become valuable strategies for helping firms compete in the markets.

According to Miltiadis D. Lytras \& Patricia that:

Competitive advantage, is a challenging task for both public and private sector organizations. Knowledge management essentially consists of tools, practices, and processes to efficiently capture, store, and share data and knowledge of individuals within an organization

Moreover, there are four factors needed to build a competitive advantage namely: efficiency, quality, innovation and customers responsiveness. They are part of lecturers' competitive advantages or other institutions that may be adopted aside from industries or products or services provided. Susan explains in her book that:

Competitive advantage is gained only when the organization selects or develops these resources and structures work tasks and the reward system in ways that motivate the team to perform well and thereby contribute to organizational effectiveness.

Although discussed separately, the picture of the generic building of competitive advantage is related one and another. For example, the superior quality may cause the superior efficiency, meanwhile, innovations may improve efficiency, quality and customer responsiveness.

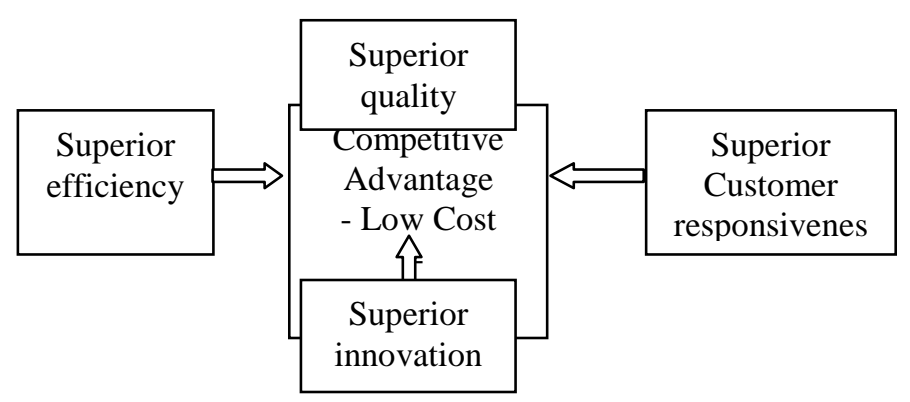

Figure 1: Building Blocks of Generic Competitive Advantage.

In building a competitive advantage, the offer of the lowest price and product diversity the most appropriate strategy to help lecturers or institution to compete in the market.

\section{A. Review Of Literature}

According to Mullins in his book Organizational Management, restructuring of organizations and reductions in staffing levels resulting from demands for improved business competitiveness and lower operating costs. This has placed greater pressures on remaining staff and resulted in a growing number of work-related health problems, work stress and a less efficient workforce.

Therefore, they have taken a competitive advantage to support very good business performance. To build such a competitive advantage, either the low-cost competition or product differentiation becomes a valuable strategy to help lecturers to compete in the market. An organizational success according to Mullis is as follows:

It will not bring sustainable competitive advantage for the future unless we build the potential of people and human capital in our organizations. This requires a new agenda, a new set of challenges for leaders and a redefined set of managerial capabilities that includes an understanding of the reality of the organization.

Based on Mullins' statement that lecturers' competitive advantage is very important to get a good quality especially at higher education level, Muhammadiyah University of Makassar needs challenges since it is the biggest private university in the Eastern Indonesia Region so that it has a specific appeal as the main target of private higher education. Muhammadiyah University of Makassar in improving its competitive power at private higher education level has analyzed its competitive advantage by showing the differences and uniqueness among its competitors. This competitive advantage is the superiority of each department which is in line with the costumers' desires such as superior skills, resources, and control. Superior skills enable Muhammadiyah University of Makassar to implement strategies to face its competitors. Skills deal with technical, managerial and operational capabilities. Meanwhile, superior resources enable it to form a superiority dimension. Superiority is the result of production with low cost or differentiation producing superiority of vales for consumers. Moreover, Zaki Malik states that: 
In some situations, companies can achieve competitive advantage by cooperating with other firms rather than competing with them. Partnership strategies are becoming increasingly popular as firms in all industries join with other organizations to promote innovation, expand markets, and pursue joint goals.

In some situations, lecturers can reach a competitive advantage. Cooperation strategies become very popular among lecturers. They make cooperation with various types of industries to improve innovations, widen market areas and to reach goals together.

Lower price makes higher education possible to give better values with lower price than the competitors for equivalent products. Differences in product appearance which is in line with the customers' preferences result in unique benefits that may cover high costs. Jonathan Smilansky states that:

Competitive advantage is to focus on critical jobs and on ensuring that the executives that occupy these jobs are as effective as possible. Succession planning processes, therefore, in the new business environment, focus not on a hierarchical concept of management layers but on the critical positions that are perceived to be key for the business's success.

Generic strategy, according to Michael Porter, consists of three basic strategies that may help lecturers to reach a competitive advantage: namely cost, differentiation, and focus. Porter names the three generic strategies. Cost advantage gives an emphasis on the making of standard products with very low cost per unit for consumers who are sensitive to price changes. Differentiation is a strategy intended to make products that provide services which are considered to be unique in all industries and it is targeted to consumers who are not too sensitive to price changes. Sabine Sonnentang in Psychological Management of Individual Performance states that

Competitive advantage is the objective of "strategic human resource management". A strategic human resource management system reflects the concerns of multiple stakeholders, is linked to the organization's specific business strategy, represents an integrated and coherent set of $H R$ practices, and it is continuously monitored, evaluated and revised.

Focus means making products and providing services that fulfill the needs of a number of small numbers of consumers. The opinion raised by Porter is in line with the following

Situation analysis leads to the formulation of explicit strategies, which indicate how the company intends to achieve a competitive advantage. Managers formulate strategies that focus on core competencies, develop synergy, and create value.

Competitive advantage in firms, according to Porter, emphasizes the importance of the strategy plans to analyze the cost and benefit to evaluate various opportunities among the existing business units and potential business among the lecturers. Moreover, Porter also emphasizes for the lecturers to transfer skills and expertise among the members of autonomous business units to make them get competitive advantages.
Dealing with Competitive advantage Thomson states

that:

In a competitive market, all firms are subject to offensive challenges from rivals. The purposes of defensive strategies are to (1) lower the risk of being attacked, (2) weaken the impact of any attack that occurs, and (3) influence challengers to aim their efforts at other rivals. While defensive strategies usually don't enhance a firm's competitive advantage, they can definitely help fortify the firm's competitive position, protect its most valuable resources and capabilities from imitation, and defend whatever competitive advantage it might have. Defensive strategies can take either of two forms: actions to block challengers and actions to signal the likelihood of strong retaliation.

Competitive advantage is a competition in the industry of lecturers, but higher education is also an educational industry and needs its lecturers to have competitive advantage either institutionally or internally. Its human resources namely the lecturers should be sympathetic in order to be able to attract the customers and win the competition by applying appropriate strategies in the field in accordance with the intended objectives. Therefore, in this global era, what higher education should possess dealing with human resources namely lecturers are competence. Competence is a set of smart actions that are done by someone as a prerequisite to be considered to be capable by the society to do task in accordance with one's field. Competence in this global era is given a high prominence since it will bear a new world, namely an open world with its various positive and negative aspects. Open world means a competitive world where all people have an equal opportunity to reach success, meaning that this open world demands human resources who are competent, productive, willing to work hard and to compete with other higher education.

Moreover, open world is supported by rapid advancement of science and technology and the lecturers with their own limitation and capability are demanded to master the science and technology. The rapid science and technology development encourage lecturers to learn sustainably to change their learning principles that have been adopted so far. It is what the higher education should pay attention. Higher education should be creative and innovative in creating an effective and interactive learning system in its effort to prepare human resources who are competent and master science and technology. The conventional and traditional learning system adopted should be changed and left. University students are not merely students, they have already been "great", meaning that they are demanded to be able to become the learning subject instead of learning objects who are always fed with science and skills by their lecturers. University students should be able to optimize various learning facility and sources and the development of technology, especially the information and communication technology. Higher education as the facilitator may facilitate students as the learning subject so that the graduates of higher education will really become ready to use and competent human resources.

Higher education as an education unit preparing and printing human resources should able to anticipate global needs. Lecturers produced should be able to compete with other lecturers and to capture challened and change them into opportunities namely to produce ready to use and superior 
alumni for the working world. Human resources produced should be really qualified and have competitive advantage. Therefore, higher education should always update its curriculum and teaching and learning strategies. Its vision, missions, and aims of it educational should lead to the creation of human resources who are competent and in line with the globalisation era.

Meanwhile, the term competitive strategy according to Philip Kotler is "a strategy which strongly places lecturers over competitors and who give lecturers' competitive advantages as strongly as possible."

The intensity of competition in an industry does not happen accidentally or is not merely a bad fate. But, competition in an industry stems from its underlying working economic structure out of the present competitors' behavior. The collective power of this power determines the ultimate potency of benefits in an industry, where the potency of the benefit is measured from its long-term return on invested capital . The condition of competition in an industry depends on five basic competitive powers as shown in Figure 2.

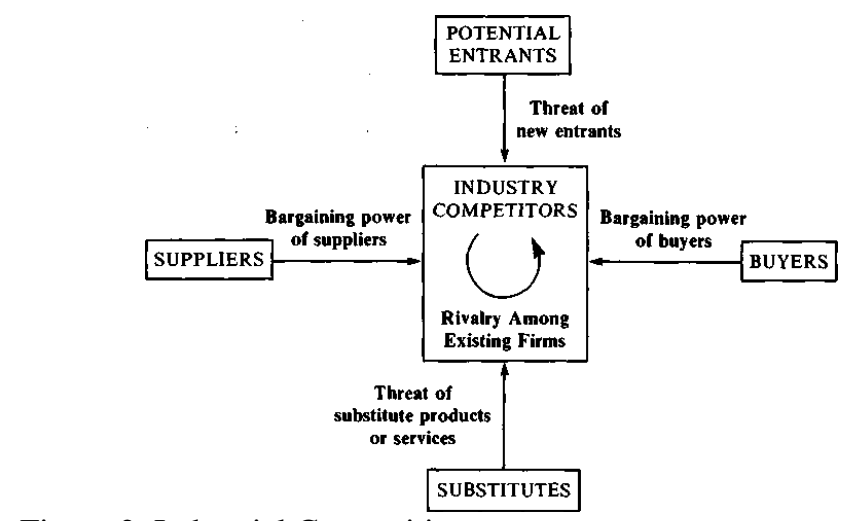

Figure 2. Industrial Competition

Therefore, the term competitive strategy is the effort made by a higher education to win the competition in a market by providing competitive strengths, analyzing its competitors and making an effective marketing strategy. A successful lecturer is the one who design and operate a system to collect sustainable information about the competitors. This shows that, according to Potter, in formulating a competitive strategy, the four factors as the key that determines the limits of what may be attained by the lecturer, should be involved. Lecturer's strengths and weaknesses are the asset profile and relative skills over the competitors, including the financial resources, technology posture, mark identification, and the like. A Lecturer's personal values are motivation and key executive needs.

- Figure 3 presents a lecturer's competitive strategy formulated internally and externally

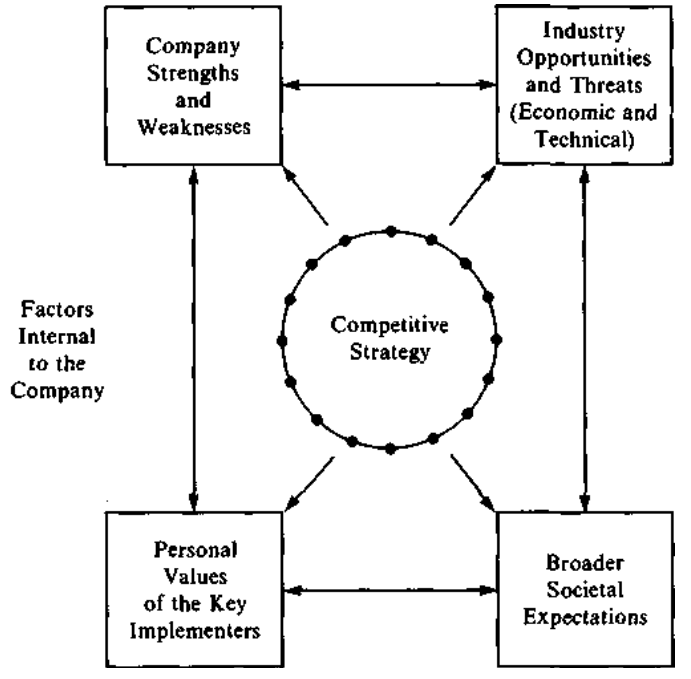

Figure 3: Context of Competitive Advantage Strategy

Competition in the education world, especially the competition among lecturers in the private higher education, lies at the quality that may be absorbed by the world of work in accordance with the department in good demand. Dealing of the need for workers especially in South Sulawesi, the graduates of Muhammadiyah University of Makassar are favorite, especially teachers and the competitor in this matter is State University of Makassar because the graduates accommodated by the government of the South Sulawesi province are those of Muhammadiyah University of Makassar and State University of Makassar. It proves that the competition to adapt the human resources either institutionally or individually among lecturers, namely the lecturers of Muhammadiyah University of Makassar and State University of Makassar really exists.

In the book "Competitive Advantage", Michael E. Porter explains the key concepts to create the competitive advantage over other rivals. Michael Porter states that "increasing scale also can make it feasible for an outsider to enter the industry with substantial competitive advantages by being the first to adopt such changes." From the statement it can be stated that it is necessary for an outsider to improve one's scale in order to be able to play an important role in an industry by making use of fundamental competitive advantages and make some changes. In this matter, central theme is that a lecturer should be really able to create and maintain his or her competitive advantages in his/her industry. Porter presents another opinion that Competitive advantage is claimed that strategy is driven primarily by industry environments, while strategy, from the resource-based view perspective, is determined by the firm's unique resources and capabilities, which in turn are seen as the main source of competitive advantage. 
Competitive advantage is the main strategy which is encouraged by the industrial environment, while, a resource and perspective-based strategy is determined by lecturers' resources and capabilities, which in turn are viewed as the main source of the competitive advantage.

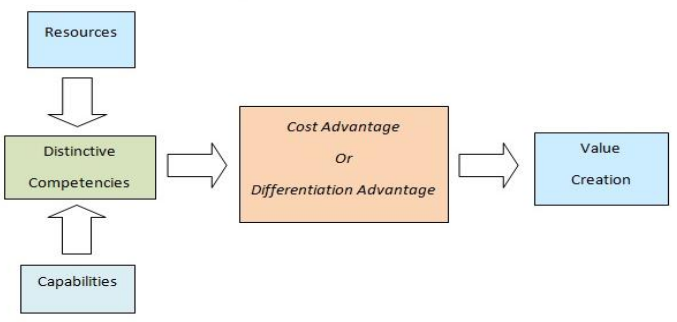

Each higher education solve uncertainty by its own ways. But, such an uncertainty in fact is less often considered in formulating competitive strategies. Explicit and implicit estimation of the future structure by conventional policies is often biased and because of this structure, their estimation mostly ignore all potential uncertainties higher education faces. It is at this point that an industrial scenario becomes important. Simply, Porter explains that the process in making an industrial scenario may be conducted as follows:

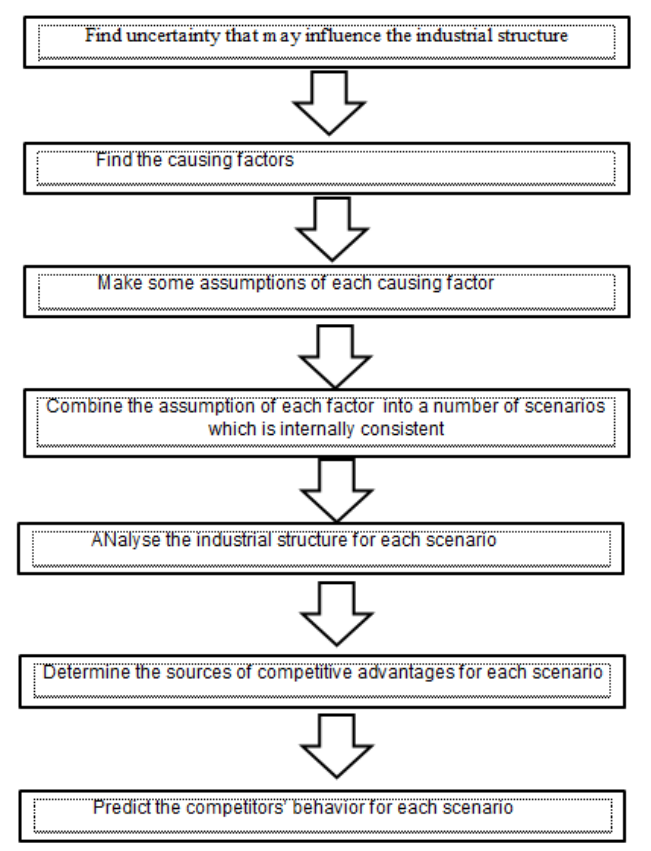

Figure 4: The Process in Making an Industrial Scenario

The process in making an industrial scenario in higher education basically is almost the same with the lecturer industry since each scenario gives a prominence to consumers so that the process made systematically gives an internal empowerment to each working unit to omit any interference from the competitors which is usually called offensive. Offensive strategy is any effort made by competitors to eliminate any competitive advantages possessed by the leader of the industry or higher education. successful offensive to the leader of higher education always requires strategic insights.

The rivals of the higher education usually should adopt different strategies to neutralize the natural advantages possessed by the leader or the higher education since the leader usually knows the competition among the existing private higher education.

\section{RESEARCH METHOD}

This article was written on the basis of study of some research results on lecturers' competitive advantages in Indonesia dealing with the application. Descriptive technique was adopted to present the results by describing the competition among lecturers in state and private higher education.

\section{RESULTS AND DISCUSSION}

\section{A. Competitive Advantage Variable}

The competitive advantage score was obtained from the results of the questionnaires consisting of 35 questions using a rating scale with 5 alternative answers of which the score is 1, 2, 3,4 and 5 each. Therefore, empirically competitive disadvantage has an empirical range from 88155 and extension of 63 . The data obtained from the field were then manually processed with the help of Excell 2010 and also the application program of SPSS version IBM. From the process, it was obtained that the competitive advantage variable had the mean value of 126,852 with the median $(\mathrm{Me})$ of 134 and Mode (Mo) of 133. The frequency distribution was entered into the table of the frequency distribution, and 5 (five) classes with minimal score of 88 and maximal one of 151, SD of 18,087 and variance of 327.140 were obtained. The distribution frequency of the score of the competitive advantage is presented in Table 1

Table 1. The distribution frequency of the score of the competitive advantage

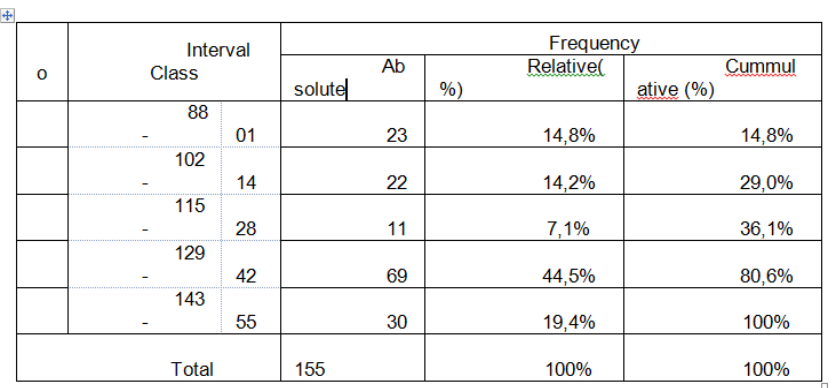

Most scores of the competitive advantage variable are at the interval class between 129-142 (44.5\%), and are followed by the interval class of $145-155$ (19.4\%), then the interval class of $88-101(14.8 \%)$. Next, the interval class of $102-114(14,2 \%)$ and the interval class with the score less than $10 \%$ are those of $115-128(7.1 \%)$. The distribution score of the competitive advantage visually is presented in the form of histogram in Figure 5.

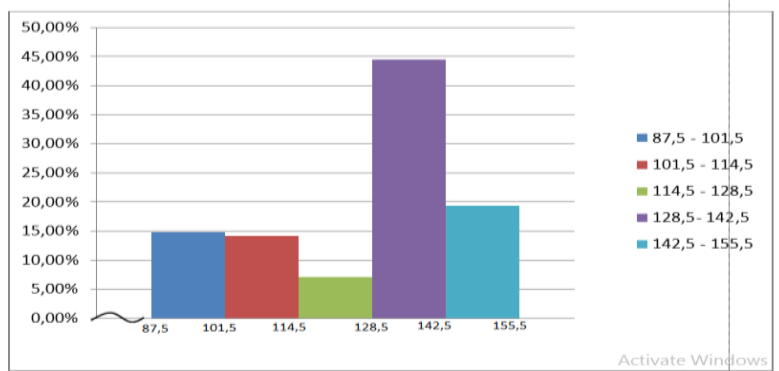

Figure 5. The distribution score of the competitive advantage 


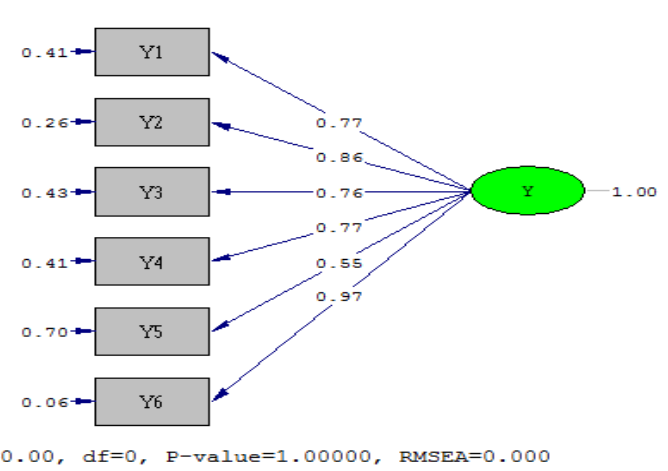

Figure 6. CFA Analysis of Indicators Forming Y

Figure 6 is the result of the Confirmatory Factor Analysis (CFA) for the competitive advantage variable. It can be stated that all indicators used did not succeed in forming the lecturers' competitive advantage variable well (fit) as shown by the value of the RMSEA of 0.000 so that in general it can be concluded that the model have fulfill a statistical requirement.

The results show that the six indicators of the lecturers' competitive advantage variable possesses the significance value which is greater than 1.960 so that it is stated to be significant. The explanation is presented in Table 2 .

Table 2. The six indicators of the lecturers' competitive advantage

\begin{tabular}{|c|c|c|c|c|}
\hline Indicator & $\lambda$ & t-count & VE & $C R$ \\
\hline $\mathrm{Y}_{1}$ & 0,77 & 10,76 & \multirow{6}{*}{$0,7 / 4$} & \multirow{6}{*}{0,942} \\
\hline Y2 & 0,86 & 10,90 & & \\
\hline Y3 & 0,76 & 9,15 & & \\
\hline Y4 & 0,77 & 10,67 & & \\
\hline Y5 & 0,55 & 7,00 & & \\
\hline Y6 & 0,97 & 14,71 & & \\
\hline
\end{tabular}

Table 2 shows that all indicators $\mathrm{Y}$ posses the loading value that is higher than 0,5 and the $t$-count which is higher than that on the t-table (2.96), meaning that it has been valid or all indicators have been able to measure Y. To measure the reliability of indicators Variance Extract(VE) or Construct Reliability (CR) may be used. The VE value of $\geq 0,50$ and the $C R$ value of $\geq 0,70$ means that it has been reliable.

\section{CONCLUSION}

The lecturers' competitive advantage indicates that their competitive advantage should be maintained and even improved by recognizing and fulfilling their needs. Their competitive advantage shows that the lecturers' objective in working and their behavior in working deal with the competitive advantage. Work plan and work activities and adaptation to and point of view of the work show a significant correlation with the competitive advantage.

\section{REFERENCES}

[1] Arthur A. Thompson, et al, Crafting and Executing Strategy (New York: McGraw-Hill), 2012

[2] Jon Ingham, Strategic Human Capital Management (USA: Oxford, Jordan Hill), 2007.

[3] Jonathan Smilansky, Developing Executive Talent (USA: John Wiley, 2006), hh.114-115

[4] Laurie J. Mullins, Management \& Organisational Behaviour (New York: Pearson Education), 2010)

[5] Michale E. Porter, Keunggulan Bersaing, Jakarta, 1994).

[6] Miltiadis D. Lytras \& Patricia Ordóñez de Pablos, Knowledge Ecology in Global Business (New York: Information Science Reference), 2009

[7] Schermerhorn, Management,International Student Version (New York: Prentice Hall), 2010

[8] Susan E. Jackson Michael A. Hitt Angelo S. DeNisi, Managing Knowledge for Sustained Competitive Advantage( USA: Jossey Bass), 2003

[9] Phapruke Ussahawanitchakit, Competitive Advantage, Thailand, Mahasarakham Business School, Mahasarakham University), 2008

[10] Ibid.p.274

[11] Ibid.p.4 